University of Wollongong

Research Online

Faculty of Engineering and Information

Faculty of Engineering and Information

Sciences - Papers: Part A

Sciences

2012

A social network model for understanding technology use for knowledgeintensive workers

Kon Shing Kenneth Chung

University Of Sydney,University of Wollongong, kchung@uow.edu.au

Follow this and additional works at: https://ro.uow.edu.au/eispapers

Part of the Engineering Commons, and the Science and Technology Studies Commons

Research Online is the open access institutional repository for the University of Wollongong. For further information contact the UOW Library: research-pubs@uow.edu.au 


\title{
A social network model for understanding technology use for knowledge- intensive workers
}

\begin{abstract}
This chapter presents a theoretical model based on social network theories and the social influence model for understanding how knowledge professionals utilise technology. In particular, the association between egocentric network properties (structure, position and tie) and information and communication technology (ICT) use of individuals in knowledge-intensive and geographically dispersed settings is explored. A novel triangulation methodology is adopted where in-depth interviews and observation techniques were utilised to develop constructs for the conceptual model which were then vetted by domain-level experts. A reliable and validated social network-based questionnaire survey is also developed to operationalise the model. Results show that task-level ICT use is significantly associated with degree centrality and functional tie-diversity; and communication-level ICT use is negatively associated with efficiency. The implications of these associations for knowledge-intensive work mean that it is important to consider the professional social network characteristics of potential users of the technology for designing ICTenabled organisations.
\end{abstract}

\section{Keywords}

workers, social, intensive, knowledge, technology, understanding, model, network

\section{Disciplines}

Engineering | Science and Technology Studies

\section{Publication Details}

Chung, K. (2012). A social network model for understanding technology use for knowledge-intensive workers. In I. Ting, T. Hong \& L. S. L. Wang (Eds.), Social Network Mining, Analysis and Research Trends: Techniques and Applications (pp. 250-269). Hershey, PA: Information Science Reference. 


\section{Chapter 15}

\section{A Social Network Model for Understanding Technology Use for Knowledge- Intensive Workers}

\author{
Kon Shing Kenneth Chung \\ University of Wollongong, Australia
}

\section{ABSTRACT}

This chapter presents a theoretical model based on social network theories and the social influence model for understanding how knowledge professionals utilise technology. In particular, the association between egocentric network properties (structure, position and tie) and information and communication technology (ICT) use of individuals in knowledge-intensive and geographically dispersed settings is explored. novel triangulation methodology is adopted where in-depth interviews and observation techniques were utilised to develop constructs for the conceptual model which were then vetted by domain-level experts. A reliable and validated social network-based questionnaire survey is also developed to operationalise the model. Results show that lask-level ICT use is signifcanty associtsod with degree centrity and

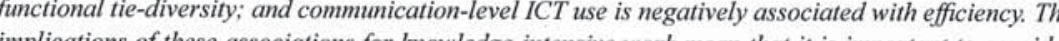
implications of these associations for knowledge-intensive work mean that it is important to consider the professional social network characteristics of potential users of the technology for designing ICT enabled organisations.

\section{INTRODUCTION}

Traditional information systems, managementand organisation science literature have documented the implementationand use of technology asbeing crucial for accomplishing organisational goals es-

DOI: 10.4018/978-1-61350-513-7.ch015 pecially when there exists a good task-technology fit. With rapid developments in technology, there exists a secondary effect of technology use in that information can now traverse spatial, structural and temporal boundares thus redefing work tructures and communication patterns (Sproull \& and information systems researchers have sough Kiesler, 1991).Consequently, information science to understand the social processes that influence the use of such information and communicatio technologies (ICT). While there are competing models and theories that explain technology use such as the technology acceptance model (Davi et al., 1989) and the social influence model (Fulk et. 1990), only a few have focused on the significance of socin nificance of social structure, social position and social ties that constitute the influence (Sykes et al., 2009; Chung \& Hossain, 2010). A key tene in this study is that understanding the relationship between social network properties and ICT use of individuals is fundamental to the design of an effective information based organisation. In thi study, the motivating questions are: at the individual level, (1) what forms of network structure are conducive to ICT use at the task and sociological levels? (2) what network position influence ICT use for task and communication purposes? (3) does personal experience or geographical colocation of peers shape ICT use more so than an individual's social network property in distributed work settings? (4) how does one account for social factors that are important for designing and implementing ICT for enhanced performance?

A theoretical framework is developed based on the theory of structural holes, strength of weak tie theory and the social influence model for understanding how individuals in knowledge-intensive work use ICT for task and communication purposes. The framework is guided by the question that if the social influence model is based on the precept that people act towards things based on the meanings that the things have for them, and that the meaning of these things is derived ou of social interaction with others and is alway changing, then a subsequent question is what form of social structures and positions constitute these interactions that influences themeaning of things? Inattempting to answer is operiptised in te context of individats is operationalised in tho context of individuals whose work is both knowledge-intensive and geographically isolated, and where the uptake of ICT has been of considerable governmental inter- est recently. In the following sections, I highlight the need for a social networks perspective int understanding $\mathrm{ICT}$ use by reviewing literature o social networks and current models for explainin ICT use along with justified hypotheses. I then describe the domain for this research followed by results and discussion.

\section{CONCEPTUAL FOUNDATIONS}

The revolution of technology and internet mean that the entire communication environment has taken on a virtual dimension. Personal relations are nolonger conducted face-to-face only and various forms of ICT are currently available for various purposes (e.g. blogs, wikis, social networkin sites like Facebook, Linkedin and so on). Thus, personal networks not only shape the ICT fo communication, but the patterns and frequency of ICT use are also shaping personal networks and re drawing social boundaries.

\section{Models of ICT Use}

In light of the above discussion, there have bee several theories and models that propose to conceptualise ICT use. Drawing on structuratio theory as an analytic perspective to view the use of ICT, Orlikowski (1992) presented a model of interaction among institutional properties, techan action. Her argument is that cection, is sustained by ICT use, which in turn mediates human action by facilitating or constraining performance. Furthermore, human action, in using technology acts upon the institutional properties of an organisation such as structure, which can, for example, be described in terms of professiona ties that link information workerstogether Insum, by such structural properties.

Otherscholas attemptedtoconceptualise ICT use based on the factors contributing to individual 
usage of ICT such as the technology acceptance model (Davis, 1989), the social inform action cessing model (Salancik \& Pfefer, 1978) and social influence mot (Fulk ( There is also a long tradition of research on impacts of ICT which examines how individuals experience information systems and technologies (Igbaria \& Tan, 1997; Mukhopadhyay et al., 1997). As this study is concerned with the network effects ofICT use at the individual level, Sproull and Kiesler's (1991) categorisation of the effects of KiCT use as efficiency (task-level) and tructure) stucture) effects is most relevant. Their work captures the two forms of effect of ICT use at both e task level and at the communication structural level. Efficiency effects are about productivity gains and social effects are about the changes instigated in the work and communication cesses as a result of frequency and patten ICT use. Therefore, in this study, by ICT use, of focus is on the use in the study, by ICT use, the focus is on the use of information and communcation technologies in a professional context fo achieving a certain set of tasks as well as for the purpose of communication to obtain information for accomplishing the task(s).

\section{Communication Structure}

and Sociology

Sproull and Kiesler's (1991) categorisation of social system effect is in line with Orlikowski's (1992) conceptualisation of technology in that the recursive process of dual change occurs at both the individual and technological level and affects each other over time. Change at the tech level can be grouped into two categrical of providing fproviding sources of information: relational and non-relational. As an example of the former, with developments in the Internet, individuals can now seek advice, information, collaborate and communicate overcoming temporal and spatial barriers as well as offer new modes of communication (synchronous and asynchronous) (Wellmanetal. 1996). Furthermore, they also cross hierarchical and departmental barriers, changestandard operating procedures and reshape work norms (Sproul \& Kiesler, 1991; Rice, 1994). Abundant studie have reported on how communication technologies have extended information reach and enable acquisition of useful information for individs Constantetal, 1994) tes (Pickering \& King 1995) thatonalcommunties (Pickering \& King, 1995) through weak ties, despite lack of personal connections with others (Constant et al., 1996). Furthermore, individuals tap into online communities and portals where benefits of social support, influence and information advantages are plenty (Butler, 2001). Such online communities and other ate online space also serve a a mon-cts within the finformal source information. Internet-based discussion groups and listservs providing summaries of communications to its members via email digests is one such example. Furthermore, company newsletters, online databases, journal repositories and online search engines such as Google also provide readily available information matching almost the same credibility and quality as from a (Henry \& Butler, 2001; Zimmer \& Hery, 2007).

While the r. While the study anticipates that those wh use both relational and non-relational sources of information will enhance performance and coordination, it is equally important to understand the factors that are conducive or contradictory to the relationship between ICT use and social structure. In other words, what forms of network at the individual the at the task and sociological levels? Alternatively, does the uptake and use of ICT foster change in network structures at both task and sociological levels? To this end, there are various theories that have been postulated. For instance, the rational choice model explains that individuals choose to use technology based on the best match the kind of technology available at between hand along with a wask at hand along with a whole set of factors such as media accessibility, usage experience, personal preference, time and cost advantages. In particu-
lar, media use theory, a proponent of the rational choice model, argues that individuals choose media through a matching process. This matching involves assessing the requirements of the particular communication task at hand and selecting a medium with communication capabilities that match the requirements (Williams, 1979). Along the same lines of the rational choice model, social presence theorists argue that individuals choose media based on social presence, which isthedere o which the medium focilites aw other person and interpersonal relationshipsduring the interaction (for example, on a scale from high to low social presence, face-to-face is highest and print media has lowest social presence) (Short et al., 1976). Yet another alternative view of the rational choice model is the information richness theory whereby communication media are arrayed along acontinuum of "inforntion richnes"baed on four factors: the degre to which the source on four factors: the degree to which the source is personal enough, speed of feedback, types of channels used for communication and the richness of the communication (Daft \& Macintosh, 1981). However, the social influence model is a more comprehensive model that encapsulates and accounts for the dynamics of social influence in explaining ICT use. While the raciont choice modelargues thatchoict model argues that choice offCT use is objectively rational and that behavior is efficiency-motivated, it fails to explain why certain individuals choose to use ICT although their motivations may no be efficiency-motivated. For example, when various forms of ICT are introduced, there is consistently growing literature that demonstrates social influence as potent predictors of t. 1990). In case of intr et al., organisations, strong ties are useful predictors fo its use (Haythornthwaite, 2002). The phenomen in such cases are beyond explanations of the rational choice model.

The social influence model (Fulk et al., 1990) starts with the basic assumption that individuals cognitively process stimuli. It argues that percetionsofICT and can be determined to a substantial degree by the attitudes, statements, and behaviours of colleagues. Colleagues exert social influence throug overt statements about characteristics of the media or tasks that individuals absorb mentally within their perceptions. The influence may also take place through vicarious learning from observing the experiences of others. Thus, if a indiving observes effective be havior by anothe servational learning produces similar behavior by that individual. In sum, the social influence model postulates that for any application, an individual's ICT use is "a function of: (a) media evaluations (perceptions and attitudes); (b) experience and skills; (c) social influence in the form of direct tatements by coworkersregading heappliction, ing

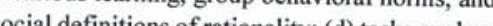
ions, and (e) tasks evaluaifferional factors such as individual (Fulk et al., 1990, p. 127).

Given these postulations from the social influence model, it helps to explain why a study in a large insurance firm found similar patterns of usage of voicemail among colleagues occupying the same structural network position (Shook, 1988). Similarly, Rice et. al. (1990) found similar patterns of email adoption among colleagues who were closely connected. In a subsequent study, Rice (1994) found that the amount and network measures of email usage were significantly associated with work and work familiarity netwo Furthermore, as ICT such as email, databases, and group decision support syster vastly in a the potential for information snowledgeincreses. Information secking in social and work contexts is thus a function of social influence in terms of social or professional network structure (Crossetal 2001) and tie diversity (Cummings, 2004). Therefore, for individuals in knowledge-intensive work, hypothesise the following: 
HIa: The number of professional ties, rather than number of co-located colleagues or experience. of an individual is positively associated with use of ICT for task-level activities in knowledgeintensive work

HIb: The number of professional ties, rather than number of co-located colleagues or experience, of an individual is positively associated with use of ICT for professional communication activities in knowledge-intensive work

\section{Understanding ICT Use}

through Social Networks

Both the technology acceptance model (Davis, 1989) and the social influence model (Fulk al., 1990) emphasise the significance of socia influence and norms in affecting ICT use. These models however, do not clearly indicte the kind of social structures or relation the or detrimental to the adoption on the contry, of the contrary, social network studies have linked the process of innovation-diffusion (e.g. medical and technological) to social processes such as how information is disseminated through socia ties and structure.

\section{Strength of Weak Ties Theory}

In a seminal work by Grannovetter (1973), it was demonstrated that individuals obtain new and novel information from weak ties rather than strong ties within the individual's group structure. The argument rests on the assumption concerning the homophilous nature of actors in a socil system, where strong ties tend to bond similar people to each other, and hat tend to cluster together mutully mutually connected. As such, information that originate and circulate at a high velocity amongst strongly tied cliques or clusters tend to become obsolete or redundant in a short amount of time. Such network-clusters or cliques of people bound together by strong ties are therefore are not conducive to channels of innovation. That is, suc networks are closed networks and are not well receptive of new information. Granovetter (1973, p. 10653) suggests that the influx of new and information must therefore come from weak (hence, the theory of the stee which , therves a ties) people from as a bridge to a different cluster of people from where the new information originates. This theory helped delineate Coleman's classical study on how physicians adopted an innovation - a new medical drug (Coleman et al., 1957) and on how individuals found jobs (Granovetter, 1995). Weak ties also account for the diveter, of information which is useful for inversity diffusion and $\mathrm{know}$ is useflion Cross, 2003; knowledge sharing (Cummings \& Cross, 2003; Cummings, 2004). More recently, Obstfeld (2005) and Tortoriello and Krackhardt (2010) have similarly argued about the nature of diversity of ties that affect the generation of innovations through the existence of the relations of the "third who joins". Formally stated:

H2: Tie diversity is positively associated with ICT use at both the task and communication levels.

\section{Structural Holes Theory}

A criticism of the weak tie theory is that it implies hat the more individuals "bridge" better they are in receiving nove adopting new adoptions. Burt (1992) lotion or criticises the theory in haw (192) however criticises the theory in that weak ties are just "the chasm spanned and the chasm itself' and that the chasm itself provides opportunities for information benefit and control. Burt's (1992) theory on structural holes offers a novel and interesting perspective in explaining why some individe perform better and others do not. extends Coleman at 's (1957) sudy by ing an explonater ing an explanation of why social processes such as innovation diffusion may occur faster from a structural positional point of view rather than from a relational perspective. The theory is linked to personality theory suggesting that persona the individual is connected to are surrounded by

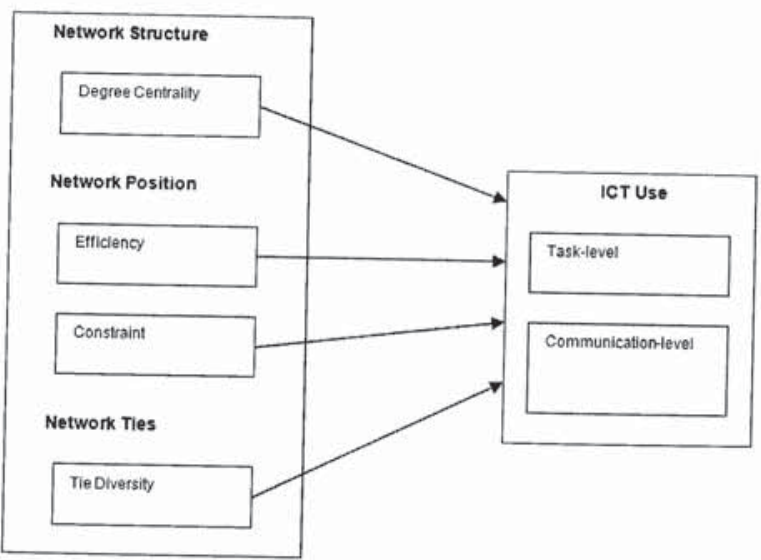
attributes (such as locus of control, leadership skills, ability to perform well) of an individua is associated with structural autonomy - a optimal situation where an individual benefits from non-redundant information benefits. Burt (1992) argues that the structural configuration of an individual's social network wich provides optimised "brokere" position is wh dictes optimised "brokerage" position is what dictates structural advantages such as information novelty and control. The bridging of connection to other provides opportunities; the lack of connections among those others is the holes in the structure (and therefore, structural holes). Individuals who attain structural autonomy are those who bridge all structural holes while the groups to whom structural holes. Therefore, individuals who are well connected to groups who are themselves not well connected are considered efficient because the structural holes offers brokerage opportunities such as information about new technologies. Conversely, individuals who are connected to those clusters of individuals in a way that it len

Figure 1. Social Networks Model for Understanding ICT Use

back to the same contact are said to be highly constrained. Therefore, I hypothesise:

H3: Efficiency is positively associated with ICT Use at both the task and communication levels

H4: Constraint is negatively associated with ICT Use at both the task and communication levels

\section{Towards a Social Networks}

\section{Model for ICT Use}

A fundamental assumption of mostsocial network research is that individual outcome such as coordination or performance is influenced by the inerplay of both network structure and tie correlates, autonomous of the medium that conduct the relations. Most studies pertaining to social networks and performance have either focused on the impact of network structure or on the effect of tie strengths within organisation ever, most of these network studies have beenever, most of these network studies have bee conducted isolating the fact that contemporary information and communication (ICT)media play 
no significant role in the creation and maintenance of social ties - the fundamental relations that connect individuals spanning geographical distances. While most studies have assumed relations being conducted face-to-face, another criticis is that the studies formallyemphase in of one strand of tie - often work relations, therefore neglecting the multiplex character of personal networks, which tend precisely to intersect several social relations (Licoppe \& Smoreda, 2005). Furthermore, individuals often work within a network of informal links that fits into a larger social structure. Such ties are generally geographically dispersed, specialised gnd connected by ICTs holl nected by IC Ts that facilitate communication and information transfer. This study is an attempt to address part of the gap and therefore outline the conceptual model.

\section{METHODOLOGY AND}

The domain for the study is the rural general practitioners (GPs) in New South Wales (NSW), Australia. Rural GPs are considered knowledge intensive workers because of their extensive medical expertise, high patient to GP ratio, provision of diverse healthcare services and so on (Humphreys \& Rolley, 1998). In knowledge-intensive knowing where and whom to obtain info work, from is wucial for perom from is crucial for performance. Yet, problem such as obsolescence with modern technology, lack of association with professional peers, an isolation from community hinder performance. In the past years, the Australian government initiated the "practice incentive programs" that fund doctors up to $\$ 10,000$ AUD each for computerizing the practices (Strasser et al, 2000). Hown is known abou the focters a in in such cases. These issues provide justification for the rural GPs as knowledge-intensive work subjects for this study (Choudhry etal., 2005) and make it potentially important as well.
A triangulation methodology consisting of two major phases of data collection was used for the study. Firstly, qualitative interviews were held with seven GPs, some who had dual job functions such as university honorary associates and lecturer. The qualitative interviews were semi-structured and held for at least an hour with each of the interviewees at appointed times over a two month period. The qualitative interviews were useful for exploring validity and revis of ICT and social network cony rets of ICT and social network constructs used in the study. The interviews were audio-recorded, transcribed and summarised as contact summary notes. Pattern-coding and memo-ing techniques were used to analyze the data. The analysis was used in conjunction with the existing literature to develop a conceptual model for the study.

Following on, an initial questionnaire survey was developed and pre-piloted amongst a group of 5 students within the research laboratory. Ten copies of the survey were then sent out to rural GPs, with only three who responded. With low
Gesies of the survey were then sent out to rual response rates, experts in the domain of general practice, including former presidentof ruraral tor's association in Australia, professor and head of discipline of general practice in a renowed GPs were consulted about the survey instrument. Subsequently, the research design and theoretical constructs were further refined. The experts also vetted the instrument, which was then pre-tested for comprehension and ease-of-use. The general response from them was that the design of the network component in the survey was visually complex and confounding As this not only deters respon and confounding. cognitive lod to survey corplest cognitive load to survey completion, advice an suggestions from the experts were accepted an the survey was modified accordingly. The second version of the survey was designed to cater for improved ease of comprehension and completion. Attribute items such as asking whether the GP were trained overseas or locally were included. Other items to determine whether they were accredited with fellowships from the RACGP(Royal
Australian College of General Practitioners) and ACRRM (Australian College of Rural and Remote Medicine) were also included in order to allow for cross demographic comparisons (although not shown in this study). The survey was piloted to 136 rural GPs practising in two different divisions of rural general practic December 2006 to February 2007. 56 agreed to fill out the survey thus achieving a response rate of about $41 \%$. The survey was mostly personally administered in order to allow for capturing of survey duration, respondent reaction and errors in the survey. Only one was administered through telephone and five others through postal mail.

After making cosmetic refinements, a final questionnaire was posted out to $1488 \mathrm{GPs}$ in the remaining fifteen divisions of rural general practice in NSW. Telephone calls were made to the practices two weeks in advance to gauge GPs' likelihood of survey response before the actual mail-out. Follow-up calls were made reminding those who agreed to do the survey two weeks after the mail-out A total of 110 rurlGPspaticipated in the study achieving a response rate of $7.8 \%$.

\section{Semi-Structured Interview Questions}

In keeping with the direction of the constructs of the study, semi-structured interviews were conducted with a sample of GPs for the conceptual development of the theoretical model. There were three major categories of questions. The first entailed generic questions about the GP's demographics (e.g. professional background and history; information about current practice; the daily workflow of a rural GP, etc.). The second category related directly to questions about social and professional networks of the GP interviewed. The questions are listed below and it is to be noted that they served as a guide in the semi-structured interview process (the reader will note this in the form of italicised statements) as opposed to a rigid structure:
1. From time to time, you may come across difficulties in your practice as a GP. Do you seek help in professional matters from other people? (Professional matters need to be explained to the GP as discussing about activities or information that are related to the provision of medical and preventative health care.

Who are the people whom you consider important for the provision of your medical practice and service? These people may be professional (e.g. nurses, other GPs, Specialists, etc.) or non-professionals (e.g. family, relatives, friends).

3. In your opinion, are social networks an important requirement in terms of task-based activities or contextual-based activities?

The third category of questions related to the use of ICT by the GP for both work practice and communication for work purposes. The questions are listed as below:

Information and Communication technologies are defined in this study as the technology that facilitates the transfer of information and communication to and from the General Practice. Video conferencing, satellite communications, PDAs, Email and so on are examples of ICT. ICT is also to be defined more narrowly.

What mediums of ICT are used in the practice? Identify which ones are most useful in context of their workflow.

2. Are the ICTs usually used for administrative and functional tasks (e.g. patient record keeping, clinical decision systems) or for social tasks (e.g. email, discussion forums, searching for information from the internet)?

3. In your opinion, do you feel that ICTs are beneficial for the performance of your work? (Relate this to the context of the workflow they described). 
4. Are ICTs important for establishing and maintaining a sense of connectedness especially in rural communities?

\section{Egocentric Network Measures}

I utilised the egocentric approach for collecting network data because of its practicality and feasibility. In this approach, the actor of interest is referred to as the "ego" and the actors referred to by the "ego" as his affiliate, advisor, friend, or relative, are known as "alters"(Scott, 2000). Name generators are used in order to elicit alters'names. In this study, I used the following name generator to elicit names from a GP's professional network:

'By 'professional network', we mean professional people whom you associate, interact or work with for the provision of care to patients (e.g. nurses, admin staff, specialists, pathologists, doctors etc.) Looking back over the last six months, please identify people (up to 15 maximum) who are important in providing you with information or advice for providing care to patients."

Name interpreter questions are also commonly asked to elicit some attribute data about the alters and ties. In this case, I requested GPs to indicate the occupational code (e.g. nurse, practice manager, specialist, etc.) as well as the geographical location (e.g. same practice, other practice, etc.) of each alter. The strength of each tie, measured by "time known the person", "frequency of interaction", "type of relationship", and "degree of closeness" (Marsden \& Campbell, 1984) was also solicited Atribute deta about he viaemail, elephone, anc via email, telephone, and video conferencing were also included in the instrument to segregate faceto-face and ICT media interactions.

To determine the relationship between elicited alters in order to complete the network structure, I asked GPs to determine how the members of their professional network relate to each other based on a five point degree of closects seale ber a each other'. That is, for each alter nominated, the GP would determine a closeness scale for every other alter. Although this approach has been criticised in the past for its recall reliability and accuracy (Bernard et al., 1985), later studies confirmed that people also remembered long-term or typical patterns of interaction with other people rather well (Freeman et al, 1987). Furtherpe he free recall method the social networks of people whereas the fixed choice method influences people to elicit accurate information on the most important relationships (i.e. strong ties) (Hammer, 1984).

\section{Efficiency and Constraint}

Effective size is a measure of the number of alters minus the average degree of alters within the ego network, not counting ties to the ego (Burt, 1992, p. 55). Effective size of an actor's (ego) network is thus:

$$
\sum_{j}\left[1-\sum_{q} p_{i q} m_{j q}\right], q \neq i, j
$$

where $i$ is the ego, actor $j$ is a primary contact, and actor $q$ is also a primary contact who has strong ties with the ego $i$ (represented by strong tie - $p_{t i}$ ) and actor $j$ (represented by marginal tie $-m_{j q}$ ). Efficiency is measured by dividing the effective size by the number of alters in the ego's network.

Egoconstraint measures the opportunities held back by the extent to which the ego has invested time and energy in relations with alters that lead back to a single contact (Burt, 1992, p. 55). In other words, it measures the extent to which the ego's connections are to others who are connected to one another. Constraint on an actor's network is defined as:

$$
\left(p_{i j}+\sum_{q} p_{i q} p_{q j}\right)^{2}, q \neq i, j
$$

where $i$ is the ego, actor $j$ is a primary contact, and actor $q$ is also a primary contact who has strong ties with the ego $i$ (represented by $p_{\text {iq }}$ ) and actor $j$ (represented by $p_{v e}$ ).

Degree Centrality

Degree centrality $\left(\mathrm{C}_{D}\right)$ is measured as the count of the ties (a) to the ego $\left(p_{k}\right)$ (Freeman, 1978). In graph theoretical terms:

$C_{D}\left(p_{k}\right)=\sum_{i=1}^{n} a\left(p_{i}, p_{k}\right)$

where $\mathrm{a}\left(\mathrm{p}_{i} \mathrm{p}_{k}\right)=1$ if and only if and are connected by a line, 0 otherwise.

\section{Tie Diversity}

Diversity is measured using an entropy-based diversity index developed by Teachman (1980):

$$
H=-\sum_{i=1}^{s} P_{i}\left(\ln P_{i}\right)
$$

where if there are $N$ possible states in which the system can be, $P$, is the probability that the systen will be found in state $i$, the only exception being when the a state is not represented in the case of which the value is 0 (Ancona \& Caldwell, 1992). Tie Diversity in this study is measured in terms of functional (occupational) and geographical diversity. Therefore, if a GP has ties to professionals from diverse occupations, her functional diversity would be high. Similarly, if a GP ha ties to professionals who are from differing cities and towns, her occupational diversity would be considered high.

\section{ICT Use Items}

ICT use has been primarily ascertained by measuring the attitudes of individual users in term of tasks for which it is used, the frequency of use, and perceived ease and comfort of use. Such attitudes of individual users towards ICT are quite important, mainly because a positive attitude is usully indicative of technology acceptance is usually indicative of technology acceptance (Mahmood et al., 2000), which in turn allows the user to believe that using the ICT would enhance his or her performance (Davis et al., 1989). The premise of measuring attitudes stems from the theory of reasoned action which describes an attitude as a "predisposition to respond favorably or unfavorably to an object, person, event, institution, or another discriminable aspect of the instion, individual's world" (Ajzen, 1988). Therefore, this study argues that attitude towards behavior is direct determinant of the behavioral intention to perform the behavior

In this study, ICT includes computers, technological software applications and system such as Medical Director (a customised medical practice software popular among GPs), email, practice stwa popur video conference and so on, Based on Sproull of ICT use as efficiency (task-level) and social (communication-structure) effects, ICT use in this case was divided into context-specific ICT use (or task-level activities - e.g. clinical tasks) and internet-related ICT use (communication and task-level activities). Task-level measures were based on the reliable and valid item sets used by Western et al (2001). Internet-related ICT use items were adapted from Andrews et al's (2004), developed by the University of Kentucky's Department of Family Practice in a project supported by the Agency for Healthcare Research and Quality (AHRQ) in the US (see Table I). 
Table 1. ICT Use Items

\begin{tabular}{|c|c|}
\hline Task-level ICT Use & Internet-related ICT use \\
\hline Generating health summaries & Accessing medical journals (e.g. BMJ) \\
\hline Recording progress notes & \begin{tabular}{|l|} 
Accessing databases (e.g. PUBMED) \\
\end{tabular} \\
\hline $\begin{array}{l}\text { Using decision support functions to help you solve diagnostic problems or make } \\
\text { decisions about dispensing or treatments }\end{array}$ & Accessing clinical guidelines \\
\hline Writing prescriptions & $\begin{array}{l}\text { Accessing evidence-based medicine related infor- } \\
\text { mation (e.g. InfoPOEMS) }\end{array}$ \\
\hline $\begin{array}{l}\text { Accessing educational material } \\
\text { for patients }\end{array}$ & $\begin{array}{l}\begin{array}{l}\text { Communicating with professional associations } \\
\text { (including email) }\end{array} \\
\end{array}$ \\
\hline $\begin{array}{l}\text { Receiving or storing information electronically such as pathology results and } \\
\text { reports }\end{array}$ & Continuing medical education (CME) \\
\hline Preparing referral letters for patients & Professional development \\
\hline \multirow{3}{*}{ Running a recall system to remind patients to return for routine tests } & Finding information to help patients \\
\hline & Email with colleagues \\
\hline & Communicating with special interest groups \\
\hline
\end{tabular}

ICT use was measured on a 5 point Likert scale ranging from "daily use" to "never". Both the eight task-level ICT use (Cronbach's $\alpha$ "
0.942 ) and ten internet-level ICT use items (Cronbach's $s=0.090$ ) its

\section{RESULTS}

The results of the study are broken down into two phases: (i) results from the interviews and (ii) results from the survey questionnaire.

\section{Qualitative Results: Semi-}

\section{structured Interviews}

In terms of the workflow of general practice, there was wide consensus amongst the interviewee about the processes, activities and flow of work In sum, it is listed as below and is consisted with the general practice literature (Usherwood, 1999):

1. Patients book an appointment

2. In exceptional cases, patients walk in

3. When patient gets called, the doctor pulls up the patient's file or creates a new one.

4. GPs consult with the patient for an average of 10-15 minutes. Sometimes, it is $30-40$ minutes in rare cases.

5. According to the nature of the consultation, the payment(s) are made by the patient.
6. After the consultation, the GP records the details into paper (or electronic records (although very seldom)).

7. If drugs are ordered, the prescription will be given to the patient.

8. In some cases, patients are referred to the specialists (e.g. Pathology labs).

9. Investigations are then faxed or electronically faxed to the surgery (or medical centre).

When asked about the topic of the importance of social and professional networks in their of the importance of collegin peers, finds and to some work, especially given the context of rural practic where most GPs practice in isolation. Although GPs don't often have the chance to meet in rura areas, they highlight the importance of rural GP conferences, meetings and even social gatherings for the purpose of medical information and knowledge updates. As one GP puts it,

"Because the senior GPs have practised for over 37 years, they know anyone who walks in the practice, there appears to be a consistent notion door...so I look forward to getting help from the two senior GPs in my practice and also from the practice manager...

GPs usually have a monthly regional meeting where updates are provided. Most of them come re the even the evening. At the same time they get a dose of continuous medical education. So that kind of social network is important and I think that it will give rise to an improvement of their performance to some extent because they would have had a talk with their specialist or fellow GP. Sometimes, I also remember things (that are useful) that I chat to my friends when I meet."

In terms of ICT use, there is also a genera consensus that ICT and task based activities do not seem to be as streamlined nor well fit with each other. For instance, in one of the project called the "Skin Cancer Project" for rural areas, most of the doctors do not use coding and use free-text to enter notes. The reconds are entered in the progress notes section and although it is possible to access them by SQL, the access is restricted and encrypted by password. Coding of the records using medical codes will streamline data retrieval and also allow for analysis later on. Furthermore, ICT is under-utilised for the purpose for which it was designed for. For example, patholoy reports are still being handled and delivered physically althoug physically a hough te Director", a computer software program for GPs, can download them electronically. The pathology reports are still being handled physically. A GP commented that "The specialist will have to invariably type the letter on a computer and prin it and send the letter...just because the hospital is not computerised, although the same service can be provided to use MD." While most GPs commented on the best feature of MD in its ability to check for drug interactions, most also agree that they do not use computer-based resource for connecting to their social and professiona etworks, with the exception of email. The following comments highlight the importance of ICT use not just for work practice but for connecting to social and professional networks for information and knowledge updates:

"Without ICT, you cannot practice! My view is biased in that to be updated in medicine, youneed o read a journal paper every three minutes. Even hen, you are 8-10 years behind of the medical advances and developments. I don't think it is possible to practise without ICT; the patients expect you to be updated in medical know-how.

"Doctors will be isolated (in rural areas). I think the rural GPs should be given not only computers but at but at least video conferencing facilities. This is because if they need to call another doctor, they need to be able to just dial and talk to them (through video-conference). Ibelieve this is quite importan otherwise they will be practicing in isolation."

Some even identify the importance of both relational sources and non-relational sources of rinforion in the work practice. This is coninformation in their wotk practice. This is consistent with literature (Henry \& Butler, 2001) Relational information sources include both socia and professional networks of peers, colleagues, friends and families. Non-relational sources of information include books, journals, magazine and electronic resources such as websites, online discussion forums, blogs, community portals, and so on. In the words of a GP,

"When GPs are in doubt regarding a diagnosis or a problem, they always refer to specialist or their colleagues or the hospital. The other thing that would certainly do (and wish others would do) is refer to some electronic resources. For example, there is the ciap.health.nsw. gov.au website which is the most fantastic site Ihave ever seen In there is the mosif you can read most of the electronic journals and medical textbooks for free.... Thave seen 60-70\%
of the medical textbooks online and it is free for 
Table 2. Demographics $(n=110)$

\begin{tabular}{|l|l|l|l|l|}
\hline & \multicolumn{1}{|c|}{ Mean } & \multicolumn{1}{c|}{ Std. Dev } & \multicolumn{1}{c|}{ Min } & \multicolumn{1}{c|}{ Max } \\
\hline Years in Rural Practice & 20.24 & 10.44 & 1 & 50 \\
\hline Years in Current Practice & 13.63 & 10.37 & 1 & 43 \\
\hline No of GPS in Current Practice & 4.54 & 4.11 & 0 & 25 \\
\hline
\end{tabular}

all doctors. This includes books about detailed prescriptions and also the website provides you external resources as well such as PubMed."

\section{Quantitative Results: Survey}

\section{\& Social Network Analysis}

Results from the respondents surveyed indicate that the typical rural GP has been in rural practice for 20.24 , with 13.63 years in the current practice (Table 2). Although there are solo-practices (a one doctor-only practice), the typical rural GP, as indicated by the results, works with at leat 4 colleague GPs in th (or $81.8 \%$ ) are male and 20 (or $18.2 \%$ ) are female, and 85 (or $77.3 \%$ ) have hospital appointments.

Table 3 lists the descriptive statistics for the variables of interest (network structure, position, ties, and IC'T use).

Table 3. Descriptive Statistics

\begin{tabular}{|l|l|l|l|l|l|}
\hline & \multicolumn{1}{|c|}{ Mean } & \multicolumn{1}{|c|}{ Median } & Std. Dev. & Min & Max \\
\hline Network Structure & & & & & \\
\hline Degree & 8.77 & 8.0 & 3.94 & 1.00 & 15.0 \\
\hline Network Position & & & & & \\
\hline Constraint & .402 & .35 & .197 & .078 & 1.00 \\
\hline Efficiency & .475 & .40 & .297 & .067 & 1.00 \\
\hline Relations (Ties) & & & & & \\
\hline Geographic Diversity & .700 & .67 & .367 & .000 & 1.71 \\
\hline Functional Diversity & .799 & .86 & .447 & .000 & 1.58 \\
\hline ICT Use & & & & & \\
\hline Task level ICT Use & 30.37 & 35 & 10.9 & 8.00 & 40.0 \\
\hline Communication related ICT Use & 26.52 & 28.0 & 8.45 & 10.0 & 45.0 \\
\hline & & & & & \\
\hline
\end{tabular}

Given that there were no clear outliers in the data distribution of all variables and that the hisograms of the ICT use variables were fairly Pement evident that high numbers of colleagues working in the same practice is not significantly associated with extent of task-level ICT use. Also, there is a sigin terms of years in current practice and tasklevel ICT use $(r=.288, p<.01)$.

Hypothesis $\mathrm{Hla}$ and $\mathrm{HIb}$ also tests whether ICT use at the task-level and communicationlevel respectively is associated with number of professional ties (degree centrality). While there is clearly no support for $\mathrm{Hlb}$, the t-test was adopted to test (Hla) for differences between the groups of high task-level ICT use and low tasklevel ICT use on the continuous variable - degree centrality. In order to group respondents into high nificant negative association between experience
Table 4. Pearson's Product Moment Correlation ( $n=110$ )

\begin{tabular}{|c|c|c|c|c|c|c|c|c|}
\hline 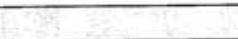 & (1) & (2) & (3) & (4) & (5) & (6) & (7) & (8) \\
\hline \multicolumn{9}{|c|}{ No of GPs in Current Practice (1) } \\
\hline Years in Current Practice (2) & -.038 & & & & & & & \\
\hline Degree (3) & .056 & .091 & & & & & & \\
\hline Constraint (4) & .130 & .185 & (.72) & & & & & \\
\hline Efficiency (5) & .145 & .146 & .18 & $\begin{array}{l}.296 \\
\left({ }^{* *}\right)\end{array}$ & & & & \\
\hline Task level ICT Use (6) & .015 & $\begin{array}{l}-288 \\
(* *)\end{array}$ & $\begin{array}{l}241 \\
\left({ }^{*}\right)\end{array}$ &. .182 & -.047 & & & \\
\hline Comm-related ICT Use (7) & -.011 & .021 & .131 & .003 & $\begin{array}{l}-216 \\
\left(^{*}\right)\end{array}$ & $\begin{array}{l}.538 \\
\left({ }^{* *}\right)\end{array}$ & & \\
\hline Geo- Diversity (8) & -.003 & .137 & $\begin{array}{l}207 \\
(*)\end{array}$ & $\begin{array}{l}-286 \\
(* * 4)\end{array}$ & .053 & .106 & .088 & \\
\hline \begin{tabular}{|l|} 
Functional Diversity (9) \\
\end{tabular} & .040 & $\begin{array}{l}.230 \\
\left.()^{\circ}\right)\end{array}$ & $\begin{array}{l}30101 \\
\left(*^{* *}\right.\end{array}$ & (-285) & -.044 & $\begin{array}{l}322 \\
\left({ }^{*}\right)\end{array}$ & .004 & (422) \\
\hline
\end{tabular}

\section{Correlation is significant at the 0.01 level (2-tailed).}

and low users, the dataset was sorted in ascending rer based on the task-level ICT use score. The median ( $M d=35)$ was selected as the cut-point to median $(M d=35)$ was selected as the cut-point to
divide the two groups. GPs with a task-level ICT divide the two groups. GPs with a task-level ICT
use score higher or equal to 35 were classified as use score higher or equal to 35 were classified as "high task-level ICT use group", all else being cans the two groups differ significantly, then there is evidence that task-level ICT use is

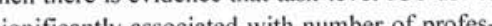
gnificantly associacd with namer of professonal ties in knowledge-intensive work. The direction of the association (i.e. positive or negative) can be evidenced in the mean score of the groups by examining which group has a higher mean. Results from the t-test (table not shown) reveal significant difference in the degree centrality of high task-level ICT users $(M=9.625$, $S D=4.16, n=56)$ and low task-level ICT users D $=4.16, n=56)$ (M) $=-2.384$ $p=.019$ (two-tailed). The magnitude of the differences in the means (mean difference $=-1.757$, $95 \%$ CI: -3.218 to -295 ) was small (eta squared $=.05$ ). Given these results, I find support for $\mathrm{Hla}$.

Regarding hypothesis $\mathrm{H} 2$ which positively associates tie diversity with ICT use at both the ak and communication levels, Table 4 confirms avery avery significant and positivecorclation between functional tie diversity and task-level ICT use $(r=.322, p<.01)$. The t-test was also used to test for differences in the functional diversity scores of high task-level ICT user groups and low task-level ICT user groups. The results confirm significant difference in the functional diversity of high ICT users $(M=9247, n=56)$ and low (M) 3.120, $p=.002$ (100-ailed). The magnitude o $-3.120, p=.002$ (two-tailed). The magnitude of the difference in the means (mean difference $=$ $.08247,95 \%$ CI: -.4207 to -.0938 ) was moderate (eta squared $=.08$ ). Clearly, high task-level ICT users have a higher mean in functional diversity score $(M=9257)$ than low task-level ICT users $M=6674)$. Given these results, there is thus par(al support for $\mathrm{H}_{2}$, none in terms of geographical diversity.

There was no support for the network-positio hypotheses - $\mathrm{H} 3$ and $\mathrm{H} 4$. It is interesting however to note that for $\mathrm{H} 3$, efficiency is negatively 
correlated with communication-related ICT use, $r=-.216, p<.05$.

Of the variables that have shown to be associated with task-level ICT use, we were curious to examine which one(s) best explain the variance in the relationship with task-level ICT use controlling for any effects that other independent variables tively reduce the number of possible explanatory variables to a smaller set in a single regression analysis, I used the stepwise multiple regressio technique with forward selection. Preliminary analyses were conducted to ensure no violation o the assumptions of normality, linearity, multicollinearity and homoscedasticity occurred.

The regression analysis identified two model of significance. In the first model, the only predictor is functional diversity, which explains $9.5 \%$ of the variance (R Square $=.095$ in Model 1) in task-level ICT use. The second model shows the entry of another variable - RACGP (a professional fellowship accreditation), the total variance explained by the model as a whole being $15.1 \%$ (R Square = 151). That is RACGP explained additional $6.3 \%$ (R Square change $=063$ in mode 2 in Table 5) of the variance in task-level ICT use, after controlling for functional diversity, $\mathrm{F}$ change $(1,106)=8.051, p<.01$. From the ANOVA table, it is clear that models $1[F(1,107)=12.350$, $p=.001]$ and $2[F(2,106)=10.607, p=.000]$ are quite significant.

In the final model (model 2), functional diversity and FRACGP were statistically significan with functional diversity recording a higher beta value (beta $=.280, p<.01)$ than FRACGP (beta $=.225, \mathrm{p}<.01)$. Therefore, one may conclude that among variables - of professional accreditation (FRACGP), network structure (degree centrality) and network ties (functional diversity), functional tie diversity makes the largest unique contribution to explanir level ICT use.

\section{DISCUSSION AND CONCLUSION}

The findings from the study provide furthe insight into the social influence model for explaining ICT use by using concepts from socia network studies as a theoretical and analytica perspective. In doing so, it has highlighted the persective. In doing so, it has highlighted the so visible relationship between social network structure, technology use and work roles (Barley, 1990). The results confirm that in knowledge-intensive work, personal characteristics such as professiona experience and number of co-located colleaguesdo not contribute towards ICT use. Rather, network properties of degree centrality and functional tie diversity are moreco the task-level with functional diversity being the most potent predictor. This contribution is nove and extends previous theoretical and domain-leve studies which document older GPs being prone to technology obsolescence and low usage of task-level ICT (Fulk et al., 1990; Choudhry et al., 2005). Also interesting is the negative corelation between ego-network efficiency and remion betwe communication-level ICT use. The general ide from current literature is that as individuals adopt more ICTs for professional communication, the have greater propensities to reach out to differen groups or individuals beyond temporal, spatial an organisational barriers. However, results show no support for this hypothesis $(\mathrm{H} 3)$. There are two possibleconjectur (1) that the rura GPs whouse high levels of communication-related ICTs are reaching out to the same group of people where the group themselves are well connected, thereby decreasing ego-network efficiency; (2) that the rural GPs already knows where to obtain information from through their professional network within the community and therefore does no need to rely solely oncommunication-related ICT. highly efficient GP is not likely to use the Internet media for communication especially where relational sources are readily known
Table 5. Regression Model for FRACGP, Degree Centrality and Functional Diversity on Task-levelICT use

\begin{tabular}{|c|c|c|c|c|c|c|c|c|c|c|}
\hline \multicolumn{11}{|c|}{ ANOVAa(c) } \\
\hline \multirow{3}{*}{$\begin{array}{l}\text { Model } \\
\end{array}$} & \multicolumn{2}{|l|}{ Perespion } & \multicolumn{2}{|l|}{ Sum of Squares } & $\mathrm{df}$ & \begin{tabular}{|l|} 
Mean Square \\
\end{tabular} & \multicolumn{2}{|l|}{$\mathbf{F}$} & \multicolumn{2}{|l|}{ Sig. } \\
\hline & & \multicolumn{2}{|l|}{1336.47} & \multirow{2}{*}{$\frac{1}{107}$} & \begin{tabular}{|l|l|}
1336,47 \\
\end{tabular} & \multicolumn{2}{|c|}{12,350} & \multicolumn{2}{|l|}{$.001(\mathrm{a})$} \\
\hline & \multirow{2}{*}{\multicolumn{2}{|c|}{$\begin{array}{l}\text { Residual } \\
\text { Total }\end{array}$}} & \multicolumn{2}{|l|}{111579.64} & & 108.22 & & \multicolumn{2}{|l|}{  } \\
\hline & & & \multicolumn{2}{|l|}{12916.12} & \begin{tabular}{|l|}
107 \\
108 \\
\end{tabular} & & \multirow{2}{*}{\multicolumn{2}{|c|}{10.607}} & \multirow{2}{*}{\multicolumn{2}{|c|}{$.000(\mathrm{~b})$}} \\
\hline \multirow[t]{3}{*}{2} & \multirow{2}{*}{\multicolumn{2}{|c|}{\begin{tabular}{|l} 
Regression \\
Residual
\end{tabular}}} & \multirow{2}{*}{\multicolumn{2}{|c|}{\begin{tabular}{|l|}
2153.85 \\
10762.26
\end{tabular}}} & 2 & 1076.92 & & & & \\
\hline & & & & & 106 & 101.53 & & & & \\
\hline & \begin{tabular}{|l|} 
Total \\
\end{tabular} & & 12916.12 & & 108 & & & & & \\
\hline $\begin{array}{l}\text { a Predictc } \\
\text { b Predich } \\
\text { eDepend }\end{array}$ & $\begin{array}{l}\text { Constant), Fum } \\
\text { Constatit) Fun } \\
\text { Variable: Task I I }\end{array}$ & $\begin{array}{l}\text { ettional Div } \\
\text { netional Div } \\
\text { evel ICTU }\end{array}$ & $\begin{array}{l}\text { ersity } \\
\text { essity, Fellow of RA } \\
\text { sse }\end{array}$ & P(Royal A & College of & ral Practitioner & sacced & & & \\
\hline & & & & Model Sur & ary(c) & & & & & \\
\hline Model & $R$ & $R^{\prime}$ & Adjusted $R^{2}$ & Std. Error & $R^{\prime}$ Change & FChange & $\mathrm{dfl}$ & $d \Omega$ & Sig. FCh & \\
\hline 1 & $322(\mathrm{a})$ & 103 & .095 & 10.40293 & .103 & 12.350 & 1 & 107 & .001 & \\
\hline 2 & $408(\mathrm{~b})$ & .167 & .151 & 10.07625 & .063 & 8.051 & & 106 & .005 & \\
\hline $\begin{array}{l}\text { a Prodict } \\
\text { b Predict } \\
\text { o Depend }\end{array}$ & $\begin{array}{l}\text { Constant, Fun } \\
\text { (Constant), Fium } \\
\text { Variable: Task ! }\end{array}$ & $\begin{array}{l}\text { netional Div } \\
\text { netional Div } \\
\text { teven ICT U }\end{array}$ & $\begin{array}{l}\text { versity } \\
\text { versity, Fellow of } \\
\text { lse }\end{array}$ & P(Royal Aus & In College of $\mathrm{G}$ & cral Practitioner & sacced & & & \\
\hline & & & & Excluded V & ables(c) & & & & & \\
\hline Model & & & Beta tn & 1 & \begin{tabular}{|l} 
Sig. \\
\end{tabular} & Partial Correl. & ation & & & \\
\hline 1 & Years in Rural & Pratico & $.174(a)$ & -1.902 & .060 & .182 & & & & \\
\hline & $\begin{array}{l}\text { Years in Curro } \\
\text { Practice }\end{array}$ & & $-.225(a)$ & -2.453 & .016 & .232 & & & & \\
\hline & Fellow of $A C$ : & & $.182(a)$ & 1976 & .051 & .188 & & & & \\
\hline & Fellow of $\mathrm{RA}$ & & $255(\mathrm{a})$ & 2.837 & .005 & .266 & & & & \\
\hline & Degree & & $.159(\mathrm{a})$ & 1.668 & \begin{tabular}{|l|l|}
.098 \\
\end{tabular} & .160 & & & & \\
\hline 2 & Years in Rural & 1 Practice & $.102(b)$ & -1.077 & 284 & .105 & & & & \\
\hline & $\begin{array}{l}\text { Years in Curre } \\
\text { Practice }\end{array}$ & & $-.172(b)$ & -1.849 & .067 & -.178 & & & & \\
\hline & Fellow of $A C$ & RRM & $.169(\mathrm{~b})$ & 1.887 & .062 & .181 & & & & \\
\hline & Degree & & $.124(\mathrm{~b})$ & 1329 & .187 & .129 & & & & \\
\hline $\begin{array}{l}\text { a Predict } \\
\text { b Predict } \\
\text { c Depence }\end{array}$ & $\begin{array}{l}\text { a the Model: (C) } \\
\text { nthe Model: (c) } \\
\text { Variable: Task ! }\end{array}$ & $\begin{array}{l}\text { Constant), Fi } \\
\text { Constant), F, } \\
\text { level ICT } \mathrm{U}\end{array}$ & $\begin{array}{l}\text { Functional Diversit } \\
\text { Functional Diversit } \\
\text { Jse }\end{array}$ & of RA & Austr & ige of $\mathrm{G}_{\mathrm{s}}$ & & & itation) & \\
\hline & & & & Coeffic & & & & & & \\
\hline Model & & & tandardized Coeffic & & Standar & dized Coefficients & & & t & Sig. \\
\hline & & B & & \begin{tabular}{|l|} 
Stu. Error \\
\end{tabular} & Beta & & & & & \\
\hline 1 & \begin{tabular}{|l|} 
(Constant) \\
\end{tabular} & 24.08 & & 2.048 & & & & & 11,762 & .000 \\
\hline & \begin{tabular}{|l|}
$\begin{array}{l}\text { Functional } \\
\text { Diversity }\end{array}$ \\
\end{tabular} & 7.863 & & 2.237 & .322 & & & & 3.514 & .001 \\
\hline 2 & \begin{tabular}{|l|} 
(Constant) \\
\end{tabular} & 22.63 & & 2.048 & & & & & 11.054 & .000 \\
\hline & \begin{tabular}{|l|l|} 
Functional \\
Diversity
\end{tabular} & 6.838 & & 2.197 & .280 & & & & 3.112 & .002 \\
\hline & \begin{tabular}{|l|l|} 
Fellow of \\
RACGP \\
\end{tabular} & 5.667 & & 1.997 & 255 & & & & 2.837 & .005 \\
\hline
\end{tabular}


and accessible; and this finding is supported in literature (Henry \& Butler, 2001).

In conclusion, the study addresses an important gap in the literature concerning understanding social processes that influence ICT use. As the technology acceptance and the social influence echnogence models lack empirical evidence from a networks perspective, this research shows that rather tha the strength of ties which functions as a conduit of novel ideas and information, it is the functional tie diversity within individual professionals networks that increase ICT use at the task-level. A limitation concerning this study is that data from only 110 general practitioners in rural NSW medical practices werecollected. This is atribut extreme difficulty in accessing the rural docto population in addition to their patient overloa and tight consultation turnaround and schedule. As such, it is important that the results and findings be interpreted within the scope of the sample. Although the results are not obviously generalisable to the larger population and the posibility of a selection bins or skewed resul possibility of a slec may be present, he fintings hever, allow us useful insights into exploring, as first step, the interplay between social network structure and patterns and frequency of ICT use of knowledgeintensive work and in geographically distributed settings. This is evidenced in the responsecollated from the qualitative interviews. Therefore, for knowledge-workers, it is important to consider he professional social network characteristics of potential users of the technology for designing CT-enabled organisations. The greater the number and diversity of peers individuals interact with translates into more opportunities to use ICT for context-specific tasks. Results from this study also show that individuals who tend to isolate themselves from peers tend to be slow adopters per The implementing ICT i such context tance. A possible sta co ICT through opinion leaders of influential colleagues rather than by doing so bureaucratically or authoritatively. Thus, an understanding of how network structure inter-relates with technology and its users would go a long way in reaping benefits required at the organisational (macro) and individual (micro) levels.

\section{REFERENCES}

Ajzen, I. (1988). Attitude Structure and Behavio Relations. In Partkanis, A. R., Berckler, S. T., \& Greenwald, A. G. (Eds.), Attitude Structure and Function. Hillsdale, NJ: Erlbaum.

Ancona, D. G., \& Caldwell, D. F. (1992). De mography and Design: Predictors of New Product Team Performance. Organization Science, 3(3), 321-341. doi:10.1287/orse.3.3.321

Andrews, J. E., Pearce, K. A., Sydney, C., Ireson, C., \& Love, M. (2004). Current State of Information Technology Use in a US Primary Care Practice-based Research Network. Informatics in Primary Care, 12(1), 11-18.

Barley, S. R. (1990). The Alignment of Technology and Structure through Roles and Networks. Administrative Science Quarterly 35(1), (Specia ase: Technoscy, Orgariztios, and lnovation) 61-103.

Bernard, H. R., Killworth, P. D., Kronenfeld, D., \& Sailer, L (1985). On the Validity of Retrosective

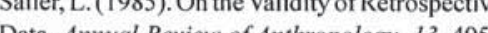
作

517. doi:10.1146/annurev.an. 13.100184.00243 Burt, R. S. (1992). Structural t Structure of Competition. Massachusetts: Harvard University Press.

Butler, B. S. (2001). Membership Size, Communication Activity and Sustainability: A Re, source-Based Model of Online Social Structures. Information Systems Research, /2(4), 346-362. doi:10.1287/isre. 12.4.346.9703
Choudhry, N. K., Fletcher, R. H., \& Soumerai, S. B. (2005). Systematic Review: The Relationship between Clinical Experience and Quality of Health Care. Annals of Internal Medicine, 142(4), 260-283.

Chung, K. S. K., \& Hossain, L. (2010). Towards a Social Network Model for Understanding Information and Communication Technology use for General Practitioners in Rural Australia. Computers in Human Behavior,

Coleman, J. S., Katz, E., \& Menzel, H. (1957). The Diffusion of an Innovation among Physicians. So-

ciometry, 20(4), 253-270. doi.10.2307/2785979 What's Mine is Ours, or Is It? A Study of Attitudes Wout Information Sharing. Information Systems Research, 5(4), 400-421.doi:10.1287/isre.5.4.400 Constant, D., Sproull, L., \& Kiesler, S. (1996) The Kindness of Strangers: The Usefulness of Electronic Weak Ties for Technical Advice. Organization Science, 7(2), 119-135. doi:10.1287/ ganization Scienc
orsc.7.2.119

Cross, R., Rice, R. E., \& Parker, A. (2001). Information Seeking in Social Context: Structural Influences and Receipt of Information Benefits. IEEE Transactions on Systems, Man and Cybernetics. Part C, Applications and Reviews, 31(4), 438-448. doi:10.1109/5326.983927

Cummings, J. N. (2004). Work Groups, Structural Diversity, and Knowledge Sharing in a Global Organization. ManagementScience, 50(3),352-364. doi: $10.1287 / \mathrm{mnsc}$. 1030.0134

Cummings, J. N., \& Cross, R. (2003). Structura Properties of Work Groups and theirConsequence for Performance. Social Networks, 25(3), $197-$ 210. doi:10.1016/S0378-8733(02)00049-7
Daft, R. L. \& Macintosh, N. B. (1981).ATentative Exploration into the Amount and Equivocality of Information Processing in Organizational Work Units. Administrative Science Quarterly, 26(2), 207-224. doi:10.2307/2392469

Davis, F. D. (1989). Perceived Usefulness, Perceived Ease of Use, and User Acceptanc of Information Technology. Management Information Systems Quarterly, 13(3), 319-340. doi: $10.2307 / 249008$

Davis, F. D., Bagozzi, R. P., \& Warshaw, P. R (1989). User Acceptance of Computer Technology: A Comparison of Two Theoretical Models. Management Science, 35(8), 982-1003. doi: $10.1287 / \mathrm{mnsc} .35 .8 .982$

Freeman, L. C. (1978). Centrality in Social Networks: Conceptual Clarification. Sociel Network Conce 8733(78) $90021-7$

Freeman, L. C., Romney, A. K., \& Freeman, S. C. (1987). Cognitive Structure and Informant Accuracy Americon Anthropologist, $89(2), 31$ doi:10.1525/aa.1987.89.2.02a00020

Fulk, J., Schmitz, J., \& Steinfield, C. (1990). A Social Influence Model of Technology Use. In Fulk, J., \& Steinfield, C. (Eds.), Organization and Communication Technology (pp. 117-140) Newbury Park, CA: Sage.

Granovetter, M. (1995). Getting a Job: A Study of Contacts and Careers. Chicago: University of Chicago Press.

Granovetter, M. S. (1973). The Strength of Weak Ties. American Journal of Sociology, 78(6), 1360-1380. doi: $10.1086 / 225469$

Hammer, M. (1984). Explorations into the Meaning of Social Network Interview Data. Social Networks, 6(4), 341-371. doi:10.1016/0378 8733(84)90008-X 
Haythornthwaite, C. (2002). Strong, Weak, and Latent Ties and the Impact of New Media. The Information Society, 18(5), 385-401. doi: 10.1080/01972240290108195

Henry, R. M., \& Butler, B. S. (2001, August 3-8). Is it Who You Know or Where You Go: August 3-8). son of Relational and Non-Relati Go: A CompariSources. Paper presented at the Acal Information agement Conference, Washington, $\mathrm{DC}$.

Humphreys, J. S., \& Rolley, F. (1998) A Modified Framework for Rural General Practice: Importance of Recruitment and Retention: The Science \& Medicine, 46(8), 939-949. di: 10.1016 0277-9536(97)00212-8

Igbaria, M., \& Tan, M. (1997). The Consequences of Information Technology Acceptance on Sub sequent Individual Performance. InformationManagement, 32(3), 113-121, doi:10.1016/50378 7206(97)00006-2

Licoppe, C., \& Smoreda, S. (2005). Are Soci Networks Technologically Embedded Networks are Changing Today with $\mathrm{Ch}$. How Communication Technology 27(4),317-335. doi:10.1016/j.

Mahmood, M. A., Burn, J. M., Gemoets, L. A, acquez, C. (2000). Variable affecting In, L. A., \& Technology End-user Satisfaction: AMeta of the Empirical Literature. International Jolysis of Human-Computer Sudies, 52(4), 751-77nal. doi:10.1006/ijhc.1999.0353

Marsden, $P$,

Tie Strength. Social Fell, K. E.(1984). Measuring

Social Forces, 63(2), 482-501.

(1997)

Output Impacton Process 1645-1659. Quality. Management Science, 43(12), 1645-1659. doi:10.1287/mnsc.43.12.1645

Obstfeld, D. (2005). Social Networks, the Tertiu lungens Orientation, and Involvement in Innov tion. Administrative Science Quarterly, 50(1)
Orlikowski, W.(1992). The Duality of Technology: Rethinking the Concept of Technology in Organizations. Organization Science, 3(3), 398-427 doi:10.1287/orsc.3.3.398

Pickering, J. M., \& King, J. L. (1995). Hardwirin Weak Ties: Interorganizational Computer- Uwiring Communication, Occupationated Organizational Change Orgmizomunities, and 479-486. doi: 10.1287/organization Science, 6(4),

Relating Electronic Mail Use and Network Structure to R\&DWork Ne Mail Use Performance.Journalof Dork Networksan Systems, 11(1), 9-29.

Rice, R. E., Grant, A., Schmitz, J., \& Torobin, J. (1990). Individual and Network Influences, J. the Adoption and Perceived Outcomes of tronic Messaging. Social Networks, 12(1), 27-55. doi:10.1016/0378-8733(90)90021-Z (I), 27-55.

Salancik,

Inforit, G. R., \& Pfeffer, J. (1978). A Social and Task 23(2), 224-253. doi:10.rative Science Quarterly, Scott, J. (2000). Social Network Analysis: A Handbook. London: SAGE Publications.

Shook, D. E. (1988). A Structural Equivalence and Contingency Theory Perspective on Media Usage and Communication Performance: The Case of Voice Messaging. Los Angeles, California University of Southern California.

Short, J., Williams, E., \& Christie, B. (1976). The Social Pychologyof Telecommunications. London: Wiley.

Sproull, L., \& Kiesler, S.(1991).Connections: New Cambridorking in the Networked Organization.

Strasser, R. P., Hays, R. B., Kamien, M., \& Carson, D. (2000). Is Australian Rural Proctice Carson, Findings from the National Rural Study. The Australian Joumal of Rural 222-226. doi:10.1046/j.1440-1584.2000.00305.x
Sykes, T. A., Venkatesh, V., \& Gosain, S. (2009). Model of Acceptance with Peer Support: A Social Network Perspective to Understand Employees' System Use. Management Information Systems Quarterly, 33(2), 371-393.

Teachman, J. D. (1980). Analysis of Population Diversity: Measures of Qualitative Variation. Sociological Methods \& Research, 8(3), 341-362. doi: $10.1177 / 004912418000800305$

Tortoriello, M., \& Krackhardt, D. (2010). Activating Cross-Boundary Knowledge: The Role of Simmelian Ties ir Simmerion Tis in the Gencration of In Academy ofManagement Journal,53(1), 167-181. doi:10.5465/AMJ.2010.48037420

Usherwood, T. (1999). Understanding the Practice: Evidence, Theoryand Practice. Buckingham: Open University Press.
Wellman, B., Salaff, J., Dimitrova, D., Garton, L., Gulia, M., \& Haythornthwaite, C. (1996). ComputerNetworks as Social Networks:Collaborative Work, Telework, and Virtual Community. Annual Review of Sociology, 22, 213-238. doi:10.1146/ annurev.soc.22.1.213

Western, M., Dwan, K., Makkai, T., Mar, C. d., \& Western, J. (2001). Measuring IT use in Australian General Practice. Retrieved 11th October, 2004, from http://www.gpeg.org/publications/ docs/ projects2001/GPCG_Project24_01.pdf

Williams, E. (1979). Experimental Comparisons of Face-to-Face and Mediated Communication: A Review. Psychological Bulletin, 84(5), 963-976. doi:10.1037/0033-2909.84.5.963

Zimmer, J.C., \& Henry, R.M. (2007).Antecedents to Relational and Nonrelational Source Use: An Exploratory Investigation. Paper presented at the 40th Annual Hawaii International Conference on System Sciences (HICSS'07), Hawaii. 